\title{
Noise propagation issues in Belle II pixel detector power cable
}

\author{
M. Iglesias,${ }^{a}{ }^{1}$ F. Arteche,${ }^{a}$ I. Echeverria,${ }^{a}$ A. Pradas, ${ }^{a}$ C. Rivetta, ${ }^{b}$ H.-G. Moser, ${ }^{c}$ C. Kiesling, ${ }^{c}$ \\ S. Rummel ${ }^{d}$ and F.J. Arcega ${ }^{e}$ \\ ${ }^{a}$ ITAINNOVA, Instituto Tecnológico de Aragón, \\ María de Luna 7, 50018, Zaragoza, Spain \\ ${ }^{b}$ GISMo, Applied Energy Division, SLAC National Accelerator Laboratory, \\ 94305 Stanford, CA, U.S.A. \\ ${ }^{c}$ Max Planck Institute for Physics, \\ D-80805 Munich, Germany \\ ${ }^{d}$ Ludwig-Maximilians-Universität (LMU), \\ D-85748 Garching, Germany \\ ${ }^{e}$ Departamento de Ingeniería Eléctrica, Universidad de Zaragoza, \\ María de Luna 3, 50018, Zaragoza, Spain \\ E-mail: miglesias@itainnova.es
}

\begin{abstract}
AвSTRACT: The vertex detector used in the upgrade of High-Energy physics experiment Belle II includes DEPFET pixel detector (PXD) technology. In this complex topology the power supply units and the front-end electronics are connected through a PXD power cable bundle which may propagate the output noise from the power supplies to the vertex area. This paper presents a study of the propagation of noise caused by power converters in the PXD cable bundle based on Multi-conductor Transmission Line (MTL) theory. The work exposes the effect of the complex cable topology and shield connections on the noise propagation, which has an impact on the requirements of the power supplies. This analysis is part of the electromagnetic compatibility based design focused on functional safety to define the shield connections and power supply specifications required to ensure the successful integration of the detector and, specifically, to achieve the designed performance of the front-end electronics.
\end{abstract}

KeYwords: Simulation methods and programs; Detector grounding; Performance of High Energy Physics Detectors; Front-end electronics for detector readout

\footnotetext{
${ }^{1}$ Corresponding author.
} 


\section{Contents}

1 Introduction 1

2 DEPFET pixel detector 2

3 Cable under study $\quad 4$

4 Multi-Transmission Line (MTL) model 5

5 Monte Carlo approach $\quad 7$

6 Common mode noise propagation 9

$\begin{array}{lll}7 & \text { Differential mode noise propagation } & 11\end{array}$

8 Currents in the shield $\quad 13$

$\begin{array}{lll}8.1 \text { Ground currents } & 14\end{array}$

$\begin{array}{ll}\text { 8.2 Radiated field (ambient noise) } & 15\end{array}$

9 Conclusions 17

\section{Introduction}

A new vertex detector based on two different technologies is planned to be installed in Belle II experiment [1] at the High Energy Accelerator Research Organization (KEK) in Tsukuba, Japan. The proposed vertex detector consists of several modules and front-end electronics (FEE) arranged cylindrically in 6 layers around the interaction point. The first two layers are based on DEPFET [2] pixel technology whereas the last 4 layers are based on double side micro strip technology.

The read-out and control ASICs of the PXD sub-detector [3] will be bump bonded on the rigid edges of the DEPFET substrate whereas in the region of the active pixel matrix the substrate will be thinned down to $50 \mu \mathrm{m}$. The FEE is subdivided into three different ASIC types, which require around fifteen different voltages to operate. This power is provided by a set of power supplies located 20 meters away from the detector using a very complex cable with more than 30 wires (shielded and unshielded) bundled all together, which run very close to other sub-detectors like the SVD (Silicon Vertex Detector) [4].

The switching process in the power supplies generates conducted and radiated electromagnetic noise that expands in a wide frequency range up to $1 \mathrm{GHz}$ [5]. Long power cables like the ones used in the PXD environment offer an entry window to common mode (CM) and differential mode (DM) produced by these power supplies, which in turn might compromise the sensitive areas of the FEE.

This paper exposes a study focused on the noise issues present in the PXD cable based on Multi-conductor Transmission Line (MTL) theory. The model used in this work corresponding to 
the Multi-Transmission Line theory was developed by [6-8]. Here, the calculation method for the cable parameters is also explained, while the measuring procedure followed in the exposed work for the cable matrix parameters is based on well validated techniques $[9,10]$.

This modeling methodology has been successfully implemented in the study of noise propagation on long power cables [11], extending its use to other applications like the space industry [12] or the automotive sector [13]. However, it is the first time this methodology is applied to such a complex power cable in a high energy physics environment.

The application of this methodology based on the MTL modeling was previously introduced by the authors in a former article [14] where the basis for the technique was explained. The present contribution continues the work presented in [14], where the theoretical basis of MTL theory in the analysis of noise propagation for high energy physics experiments was presented. The herein work is part of a project intended to characterize the electromagnetic environment of PXD and to ensure the correct integration of FEE. The PXD simulation studies will help to define the noise level present in the vertex area due to noise coupling among the PXD cable bundle as well as the noise propagation through it. The outcome of this study will provide information to address the effect of noise running through PXD cables on noise immunity levels required for the vertex FEE.

\section{DEPFET pixel detector}

The PXD consists of two layers of sensors based on DEPFET technology [15]. The inner layer consists of 8 planar sensors ("ladder"), each $15 \mathrm{~mm}$ wide, and a sensitive length of $90 \mathrm{~mm}$. The outer layer consists of 12 modules with a sensitive length of $123 \mathrm{~mm}$ and $15 \mathrm{~mm}$ width. The sensors are mounted on an integrated support and cooling structure, held by screws.

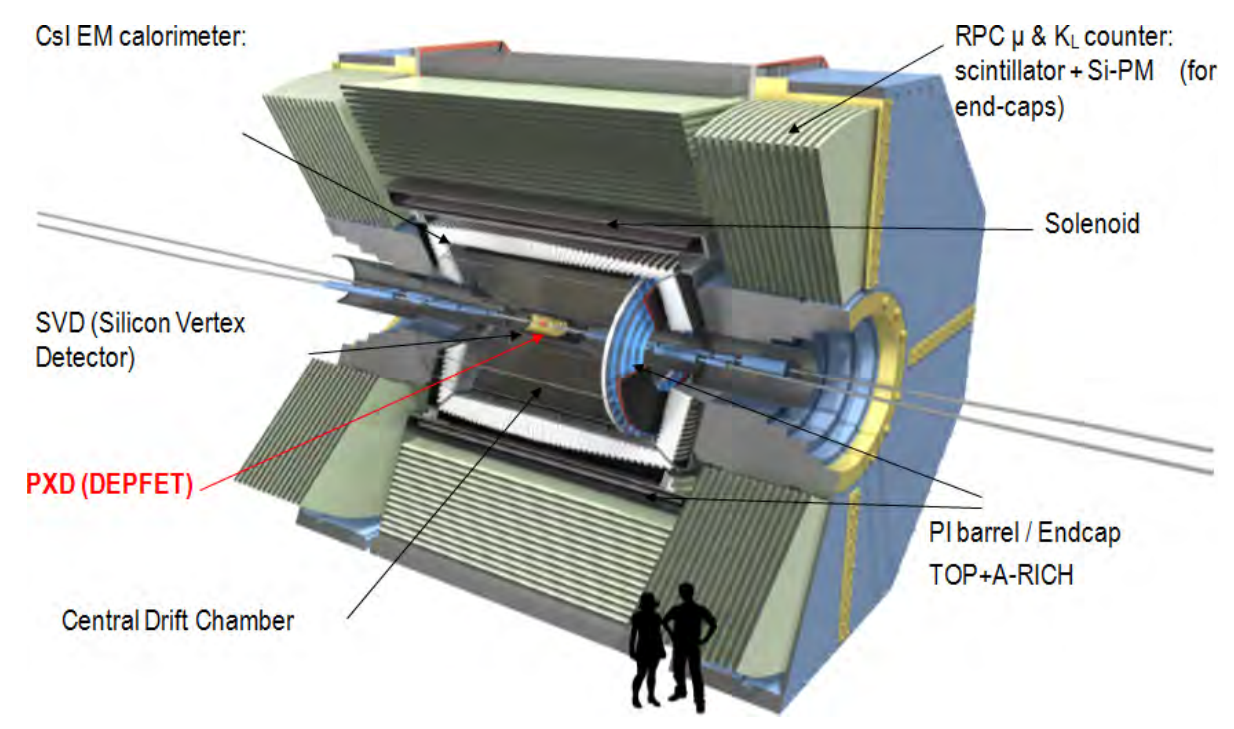

Figure 1. Belle II experiment with PXD detector.

The detector is arranged within the BELLE II experiment (figure 1), a hermetic detector system which allows the reconstruction of particle tracks after a collision, and performs the measurement of energy, momentum and charge of the produced particles. 
In this concept, the readout electronics, which needs active cooling, are located outside the acceptance region. The selected DEPFET pixels send currents to the vertically connected drain lines. These currents are processed by each Drain Current Digitizer (DCD) chips. Each DCD performs an immediate digitization of the current with 8 bit resolution and sends the data serially through many low-swing single ended lines to a third chip, the Data Handling Processor (DHP), which buffers and analyzes the digital data stream and performs a zero suppression. From there, a multi-layer Kapton cable guides the signals to a patch panel, where data are directed to the Data Handling Hybrid (DHH) which feeds the data stream via optical fiber to the data acquisition system. Power is supplied remotely by several floating DC-DC converters in a complex power distribution (figure 2).

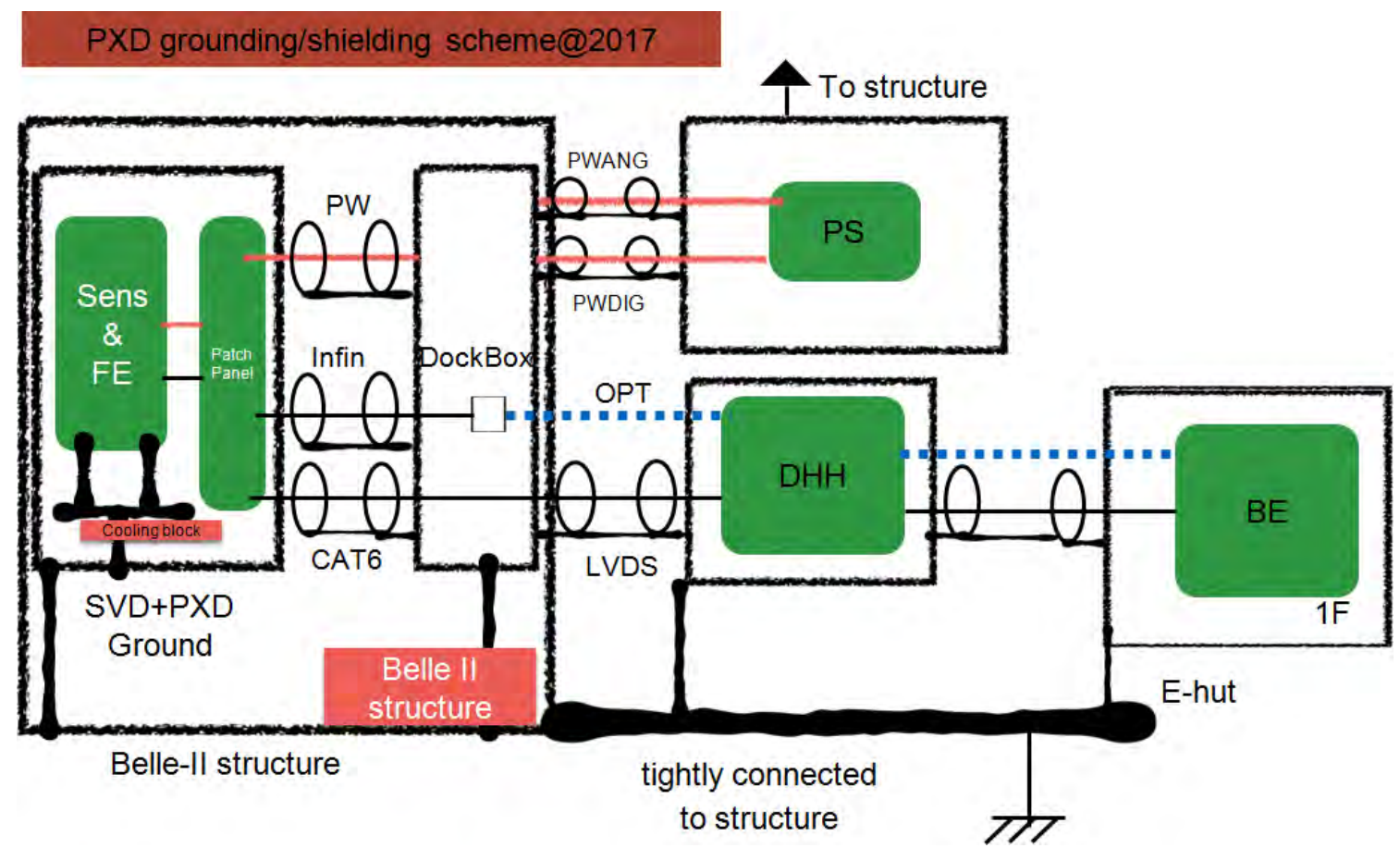

Figure 2. PXD powering scheme.

Each DC-DC feeds one set of signals, using some of the cable conductors as return. Figure 3 shows the connection of the conductors in the analogue system to some of these power supplies. As the figure shows, each DC-DC shares a return conductor with another DC-DC. These switching power supplies are one of the most important noise sources in DEPFET. The switching mechanism couples a higher amount of conductive noise than traditional linear power supplies to both the input and output terminals of the power converter unit. As a result, noise propagation along the power cables must be addressed as it has a direct impact on the noise that reaches the susceptible areas (vertex sensors and readout electronics). The cable analyzed in the present study corresponds to cable PW (brown color) in figure 2 since it provides a low impedance connection to the "external" world and it crosses all the experiment (15 meter long aprox.). Some studies have been performed on the noise propagation of long power cables [11, 16-18]. This cable however uses a very complex structure with 30 conductors and two shields, in a way that noise interactions within the cable are analyzed. 


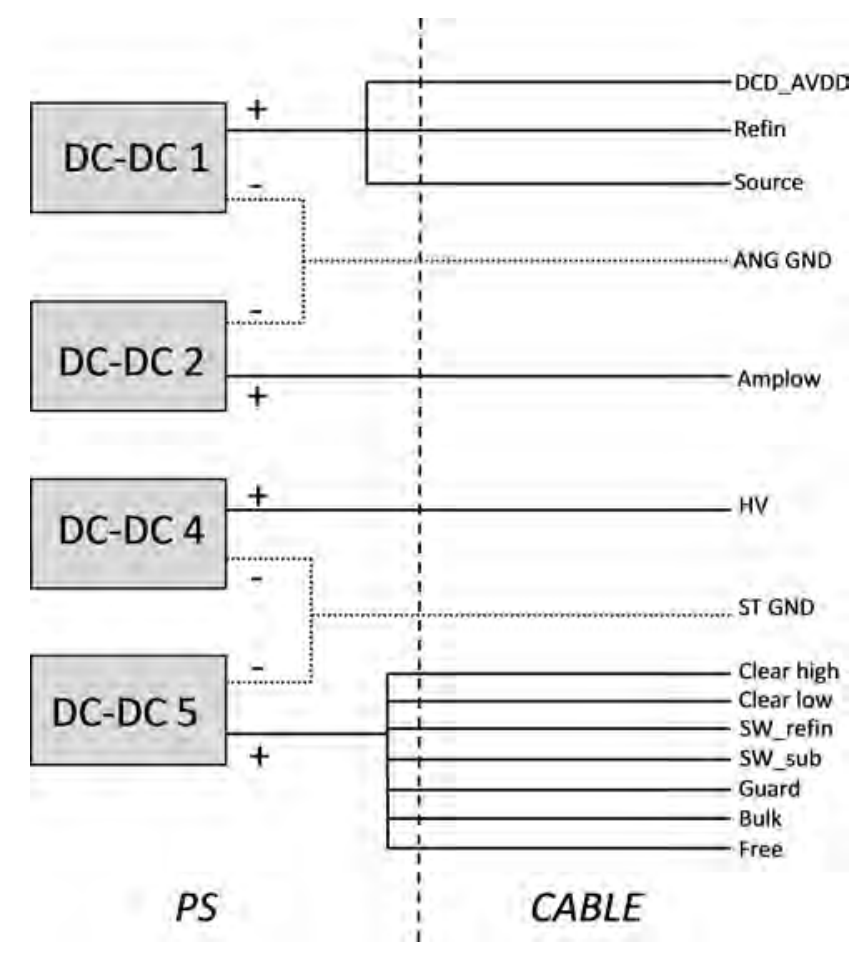

Figure 3. Power supplies connection to power cable (analogue signals).

\section{Cable under study}

The power cable comprises a group of 30 bare copper conductors $(4 \times 18$ AWG +14 AWG +20 AWG $+12 \times 2 \times 26$ AWG) gathering power, bias and sense signals. Two shields made of aluminum foil are used, one internal and one external, in a way that the cable can be divided into three systems: external, steering and internal system (figure 4, 5).
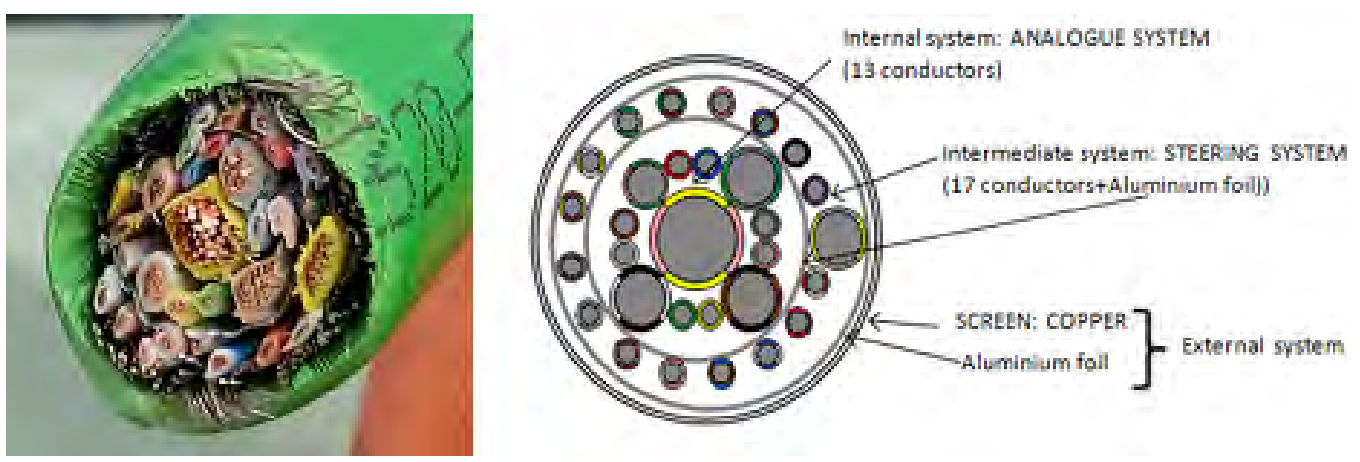

Figure 4. Power cable under study.

The conductors in the inner system wrapped by the first shield correspond to the analogue/digital power lines (only analogue or digital lines are fed by one cable at the same time) together with the sense signals and corresponding common return (labelled ANG GND or DIG GND depending on the case). Since topologies are similar for both analogue and digital systems in this cable, the 


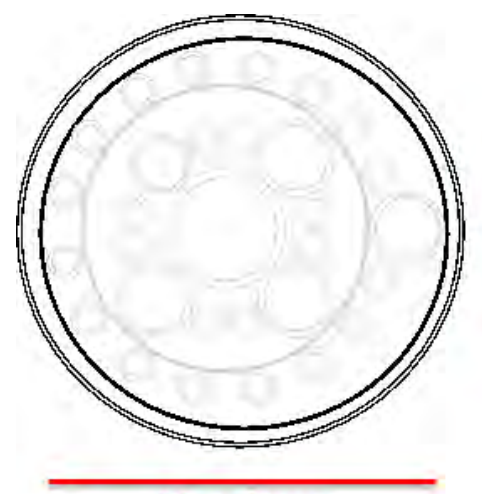

Metal tray

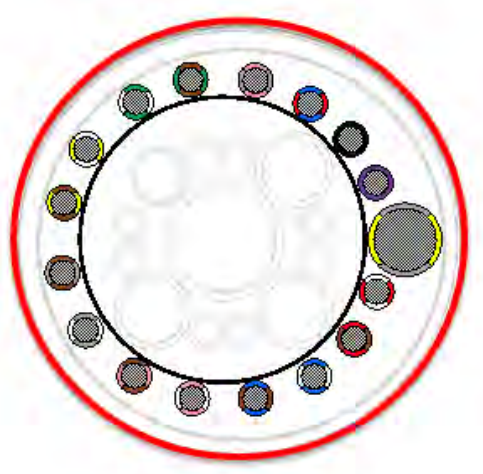

Steering system

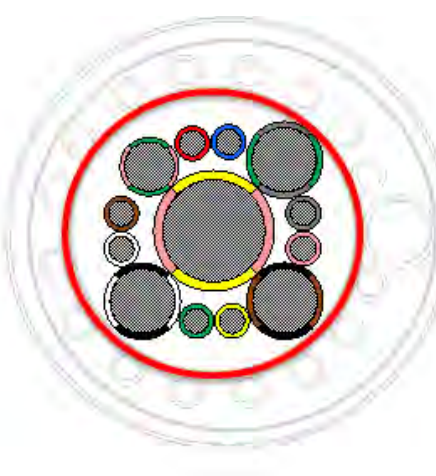

Anlg/Dig system

\section{External system}

Figure 5. PXD cable systems with the reference in red: metalic tray (external system), outer shield (steering system) and inner shield (analogue/digital system).

analogue case is used for the present study. The intermediate system groups the steering power lines along with the sense signals and common return (STGND). Finally, the external layers comprise a second aluminum foil embraced by a tinned copper braid.

\section{Multi-Transmission Line (MTL) model}

The cable performance has been evaluated using Multi-conductor Transmission Line Theory (MTL) [6-8]. This approach assumes a Transverse Electromagnetic Mode (TEM) in which the cable is modeled with line parameters per unit length (R, L, C, G matrixes). Once the boundary conditions are applied in the shape of load and source impedances, the solution is computed as voltage and current vectors in the frequency domain.

Due to the skin effect, currents and voltages on the shield can be separated into inner and outer systems (figure 6). The inner system consists of the inner conductors of the cable and the inner face of the shield as reference. The outer system models the interaction of the environment with the shield and includes the effect of propagation of signals between the shield and the structure of the system [19].

This transmission line can be modeled by a differential equation (4.1) with $z$ the coordinate along the line:

$$
\begin{aligned}
& \frac{\partial}{\partial z} V(z, t)=-R I(z, t)-L \frac{\partial}{\partial t} I(z, t)+Z_{t} \cdot I_{o}(z, t) \\
& \frac{\partial}{\partial z} I(z, t)=-G V(z, t)-C \frac{\partial}{\partial t} V(z, t)+Y_{t} \cdot U_{o}(z, t),
\end{aligned}
$$

where $Z_{t}$ is the transference impedance, $Y_{t}$ is the transference admittance, $I_{o}$ the current flowing through the outer face of the shield and $U_{o}$ is the voltage between the shield and the environment reference. The transference impedance $Z_{t}$ can be expressed as a function of the frequency $\omega[20]$ :

$$
Z_{t}=Z_{d}(\omega)+j \cdot\left(M_{h} \pm M_{b}\right)
$$




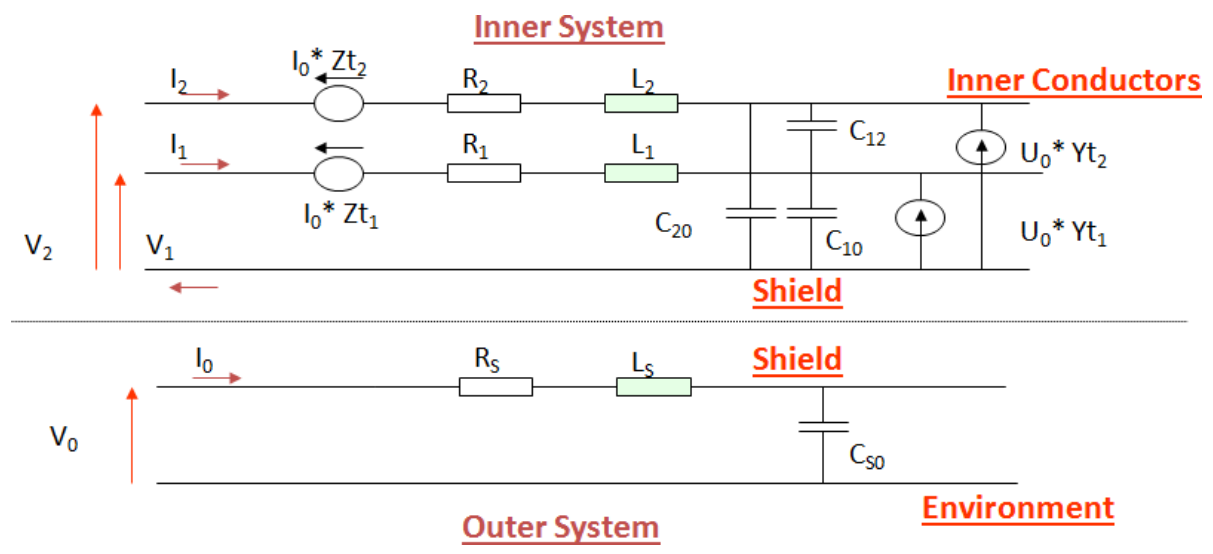

Figure 6. Transmission line model for shielded cable.

where $Z_{d}$ is the diffusion coupling component (which is due to skin effect in the shield), $M_{b}$ is the braid inductance component, defined as the coupling between the external and the internal layers of the shield, and $M_{h}$ is the aperture-coupling component, defined as the coupling through the holes of the shield. This last parameter plays an important role in the value of the transfer impedance at high frequencies.

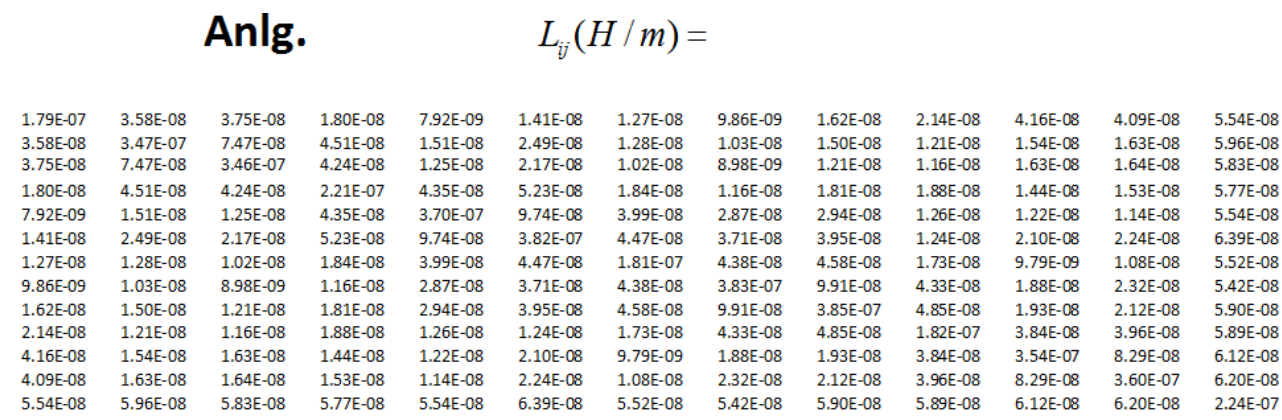

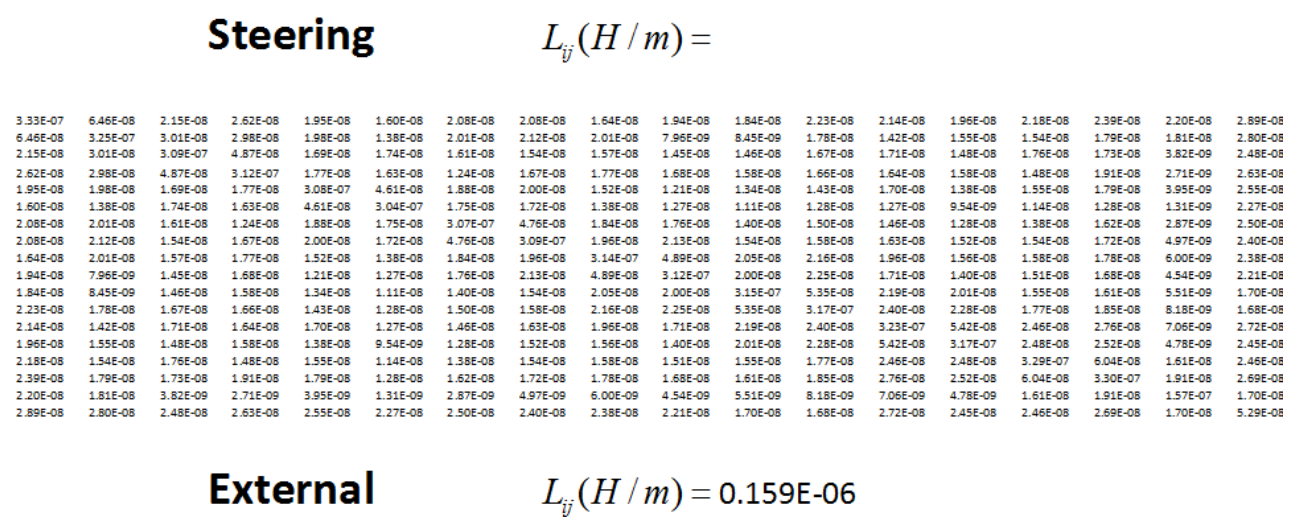

Figure 7. Inductance matrixes for the PXD power cable.

Once the resistance, capacitance and inductance are measured for each conductor, MTL matrix parameters can be built. The R-L-C matrixes for Analogue $(13 \times 13)$, Steering $(18 \times 18)$ and External $(1 \times 1)$ systems are shown in figure 7 , figure 8 and figure 9 . The rest of matrixes are introduced in 
the model along with the boundary conditions, which will be set for each simulation as they will define the noise injection in the system and the impedance found at the end of the cable.

\begin{tabular}{|c|c|c|c|c|c|c|c|c|c|c|c|c|}
\hline $3.11 \mathrm{E}-10$ & $9.23 \mathrm{E}-12$ & $1.65 \mathrm{E}-11$ & $1.67 \mathrm{E}-12$ & 4.10E-11 & $7.20 \mathrm{E}-11$ & $2.65 \mathrm{E}-11$ & $1.07 E-11$ & $9.29 \mathrm{E}-12$ & $1.23 \mathrm{E}-12$ & $2.09 \mathrm{E}-11$ & $2.82 E-11$ & $1.88 \mathrm{E}-11$ \\
\hline $.23 \mathrm{E}-12$ & $1.59 \mathrm{E}-10$ & $2.92 \mathrm{E}-11$ & $1.49 \mathrm{E}-11$ & $2.62 \mathrm{E}-11$ & $2.48 E-11$ & $5.12 \mathrm{E}-12$ & $5.83 E-12$ & $4.25 \mathrm{E}-12$ & 5.45 & $6.41 \mathrm{E}-12$ & 6.02 & $6.47 \mathrm{E}-12$ \\
\hline $1.65 \mathrm{E}-11$ & $2.92 \mathrm{E}-11$ & $1.59 \mathrm{E}-10$ & $1.44 \mathrm{E}-11$ & $6.40 \mathrm{E}-11$ & $6.44 E-11$ & $1.91 \mathrm{E}-12$ & $1.06 \mathrm{E}-12$ & $6.59 \mathrm{E}-13$ & $5.91 \mathrm{E}-12$ & $3.41 \mathrm{E}-12$ & $2.84 \mathrm{E}-12$ & $4.24 \mathrm{E}-11$ \\
\hline $1.67 \mathrm{E}-12$ & $1.49 \mathrm{E}-11$ & $1.44 E-11$ & $2.69 \mathrm{E}-10$ & $1.60 \mathrm{E}-11$ & $1.50 \mathrm{E}-11$ & 7.37E-13 & $1.84 E-12$ & $1.74 E-12$ & $5.29 \mathrm{E}-13$ & $3.97 E-12$ & $1.35 \mathrm{E}-12$ & $4.57 \mathrm{E}-11$ \\
\hline $4.10 \mathrm{E}-11$ & $2.62 \mathrm{E}-11$ & $6.40 \mathrm{E}-11$ & $1.60 \mathrm{E}-11$ & $1.63 \mathrm{E}-10$ & $3.16 \mathrm{E}-11$ & $1.68 \mathrm{E}-11$ & $5.07 E-13$ & $3.77 E-12$ & $2.63 \mathrm{E}-11$ & $2.39 \mathrm{E}-11$ & $7.62 \mathrm{E}-12$ & $5.97 \mathrm{E}-12$ \\
\hline $7.20 E-11$ & $2.48 \mathrm{E}-11$ & $6.44 E-11$ & $1.50 \mathrm{E}-11$ & $3.16 \mathrm{E}-11$ & $1.62 E-10$ & $1.81 \mathrm{E}-11$ & $5.42 \mathrm{E}-13$ & $1.30 \mathrm{E}-12$ & $2.42 \mathrm{E}-11$ & $2.49 \mathrm{E}-11$ & $7.21 \mathrm{E}-12$ & $2.61 \mathrm{E}-11$ \\
\hline $2.65 \mathrm{E}-11$ & $5.12 \mathrm{E}-12$ & $1.91 \mathrm{E}-12$ & 7.37E-13 & $1.68 \mathrm{E}-11$ & $1.81 \mathrm{E}-11$ & $3.19 \mathrm{E}-10$ & $1.71 \mathrm{E}-11$ & $1.85 \mathrm{E}-11$ & $8.01 \mathrm{E}-14$ & $1.47 \mathrm{E}-13$ & $3.10 \mathrm{E}-13$ & $3.50 \mathrm{E}-11$ \\
\hline $1.07 E-11$ & $5.83 \mathrm{E}-12$ & $1.06 \mathrm{E}-12$ & $1.84 \mathrm{E}-12$ & $5.07 E-13$ & $5.42 E-13$ & $1.71 \mathrm{E}-11$ & $1.58 \mathrm{E}-10$ & 3.07E-11 & $1.77 \mathrm{E}-11$ & $2.30 \mathrm{E}-13$ & 3.07E-13 & $1.59 \mathrm{E}-11$ \\
\hline $9.29 \mathrm{E}-12$ & $4.25 \mathrm{E}-12$ & $6.59 \mathrm{E}-13$ & $1.74 \mathrm{E}-12$ & $3.77 \mathrm{E}-12$ & $1.30 \mathrm{E}-12$ & $1.85 \mathrm{E}-11$ & $3.07 E-11$ & $1.59 \mathrm{E}-10$ & $1.84 \mathrm{E}-11$ & $1.83 \mathrm{E}-12$ & $5.20 \mathrm{E}-13$ & $2.88 \mathrm{E}-11$ \\
\hline $1.23 \mathrm{E}-12$ & $5.45 \mathrm{E}-12$ & $5.91 E-12$ & $5.29 \mathrm{E}-13$ & $2.63 \mathrm{E}-11$ & $2.42 E-11$ & $8.01 \mathrm{E}-14$ & $1.77 \mathrm{E}-11$ & $1.84 \mathrm{E}-11$ & $3.15 \mathrm{E}-10$ & $1.33 E-11$ & $1.58 \mathrm{E}-11$ & $1.72 \mathrm{E}-11$ \\
\hline 2.09E-11 & $6.41 \mathrm{E}-12$ & $3.41 \mathrm{E}-12$ & $3.97 \mathrm{E}-12$ & 2.39E-11 & $2.49 \mathrm{E}-11$ & $1.47 \mathrm{E}-13$ & $2.30 \mathrm{E}-13$ & $1.83 \mathrm{E}-12$ & $1.33 \mathrm{E}-11$ & $1.59 \mathrm{E}-10$ & 3.03E-11 & $1.99 \mathrm{E}-11$ \\
\hline $2.82 \mathrm{E}-11$ & $6.02 \mathrm{E}-12$ & $2.84 E-12$ & $1.35 E-12$ & $7.62 \mathrm{E}-12$ & $7.21 \mathrm{E}-12$ & $3.10 \mathrm{E}-13$ & $3.07 E-13$ & $5.20 \mathrm{E}-13$ & $1.58 \mathrm{E}-11$ & $3.03 \mathrm{E}-11$ & $1.54 \mathrm{E}-10$ & $1.78 \mathrm{E}-11$ \\
\hline $1.88 \mathrm{E}-11$ & $6.47 \mathrm{E}-12$ & 4.24E-11 & $4.57 \mathrm{E}-11$ & $5.97 \mathrm{E}-12$ & $2.61 \mathrm{E}-11$ & $3.50 \mathrm{E}-11$ & $1.59 \mathrm{E}-11$ & 2.88E-11 & $1.72 \mathrm{E}-11$ & $1.99 \mathrm{E}-11$ & $1.78 \mathrm{E}-11$ & $2.84 \mathrm{E}-10$ \\
\hline
\end{tabular}

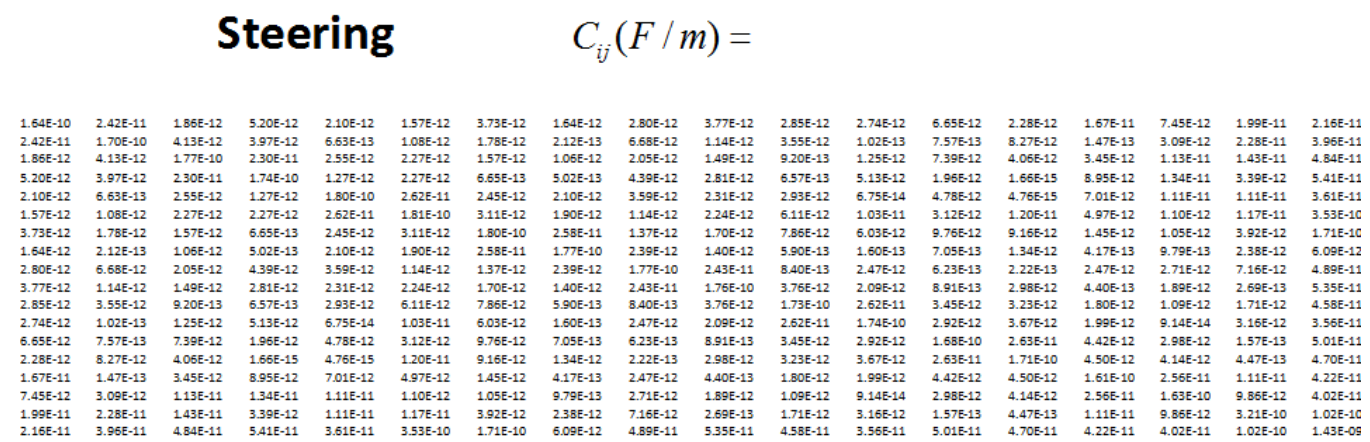

External

$C_{i j}(F / m)=69.94 \mathrm{E}-12$

Figure 8. Capacitance matrixes for the PXD power cable.

\section{Monte Carlo approach}

The analysis of noise propagation in a wire harness is strongly dependent on geometrical variables that define the characteristic matrixes of the bundle. Within these variables, the cross position of each cable is especially susceptible of suffering small changes that might introduce a certain level of variation in the final results. These variations may present a random behaviour that must be treated from a statistical point of view. Therefore, a stochastic approach is required in order to account for this uncertainty.

Among the several existing stochastic methods, the Monte Carlo method can be implemented as a way to estimate the deviation in the output results of a complex system in which the uncertainty that takes place is not easy to approach analytically [12]. In the case under study, the MTL model is used within a Monte Carlo algorithm so that the output results of the simulations already include the uncertainty of the whole process in a way that the density probability function of the noise can be obtained. Figure 10 shows the approach followed by this method. 


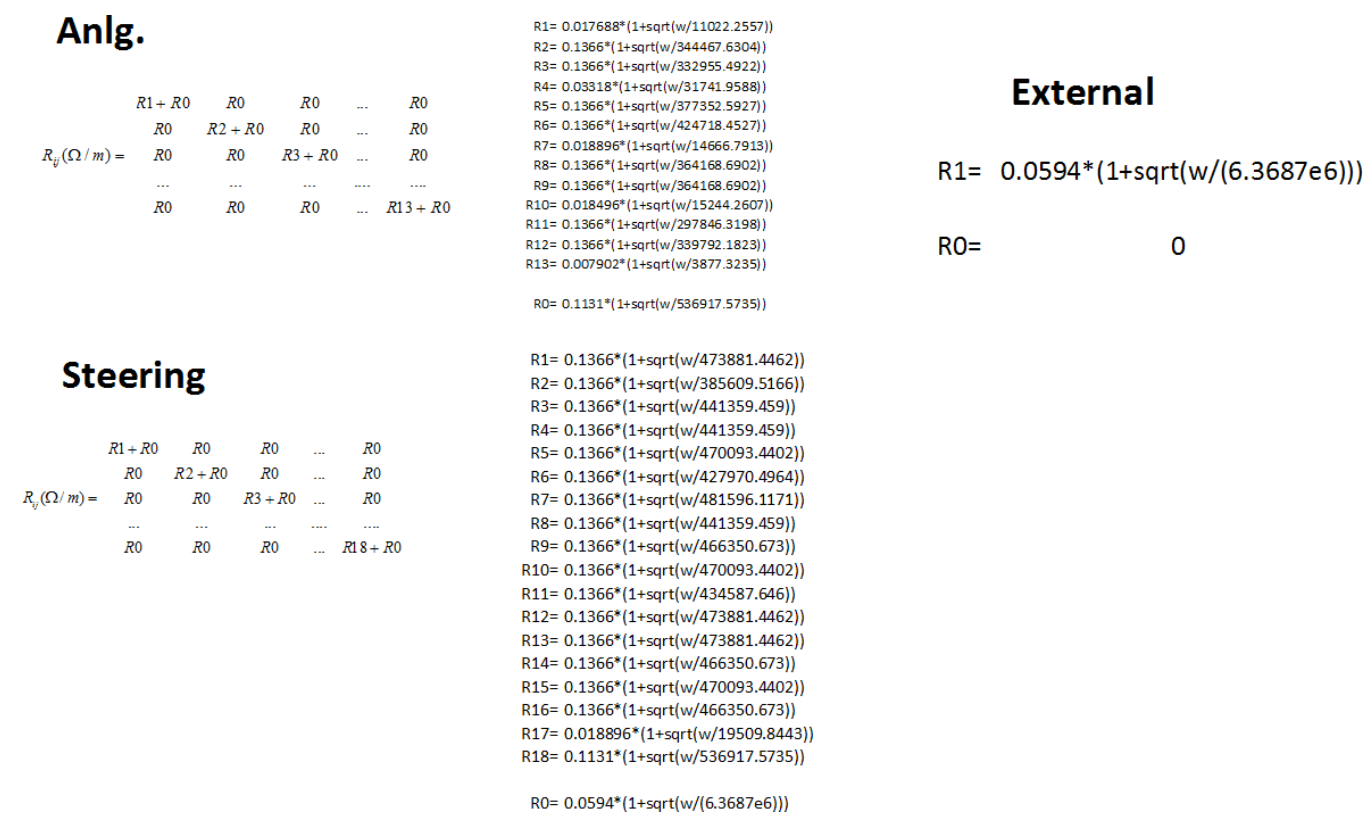

Figure 9. Resistance matrixes for the PXD power cable.

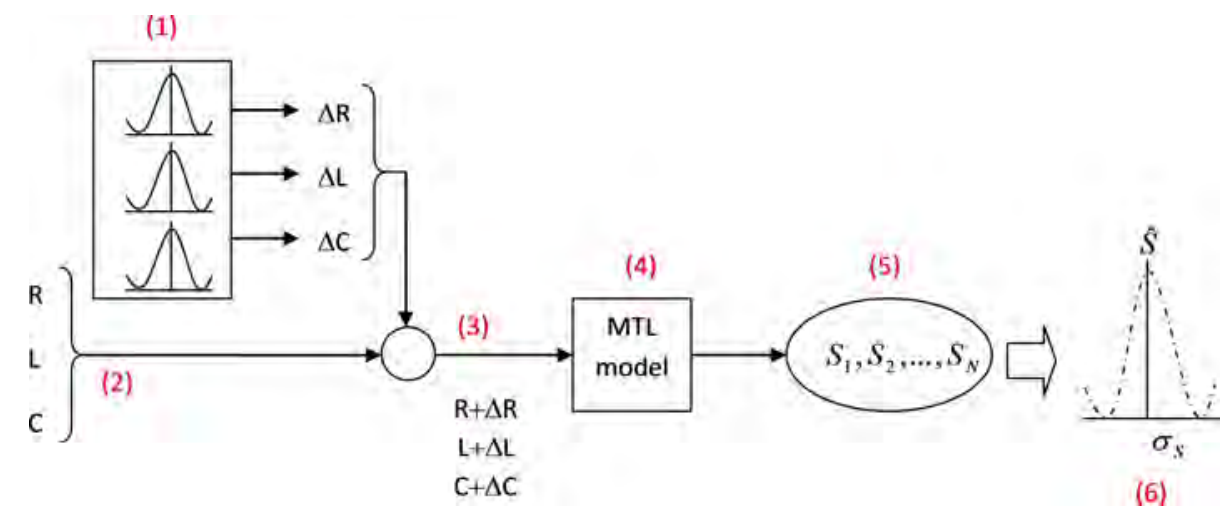

Figure 10. Monte Carlo approach.

In each iteration, a random sample is drawn from the probability function ( $\{1\}$ in figure 10) that models the uncertainty of each measured matrix. This sample is added to each measured values of $R, L$ and $C$ (\{2\} in figure 10) as a disturbance, in a way that the new values for $R, L$ and $C$ ( $\{3\}$ in figure 10) are used in the MTL model ( $\{4\}$ in figure 10) to compute a solution $S_{i}$. Once this process is performed $N$ times (being $N$ the number of samples selected for the Monte Carlo method), the resulting batch of $N$ solutions ( $\{5\}$ in figure 10) is afterwards processed to obtain an average value $S$ and its corresponding deviation $\sigma_{S}$. These two parameters can be used eventually to represent the probability distribution ( $\{6\}$ in figure 10 ) of the final solution.

In this study, 100 samples have been used. Only the average simulated curves are shown. 


\section{Common mode noise propagation}

The propagation of the common mode (CM) noise injected by power supply units is studied with the analysis of noise propagation through each line as well as noise coupling among lines. The CM voltage and current at the end of each line ( $z=L$, with $L$ the total length of the line) is measured and compared to the injected current so that voltage and current transfer functions are computed in order to quantify the noise effect on the cable:

$$
T_{c m-V}(\omega)=\frac{V_{c m}(L, \omega)}{V_{c m}(0, \omega)} T_{c m-I}(\omega)=\frac{I_{c m}(L, \omega)}{I_{c m}(0, \omega)}
$$

The terminal connections on both sides of the cables are included in the model (source terminal and load terminal) as load and source impedances defined by input / output filters. $10 \mathrm{k} \Omega$ resistances are used to model the sensing lines high impedances. Figure 11 shows the schematics used for the DC-DC 1 and 2.

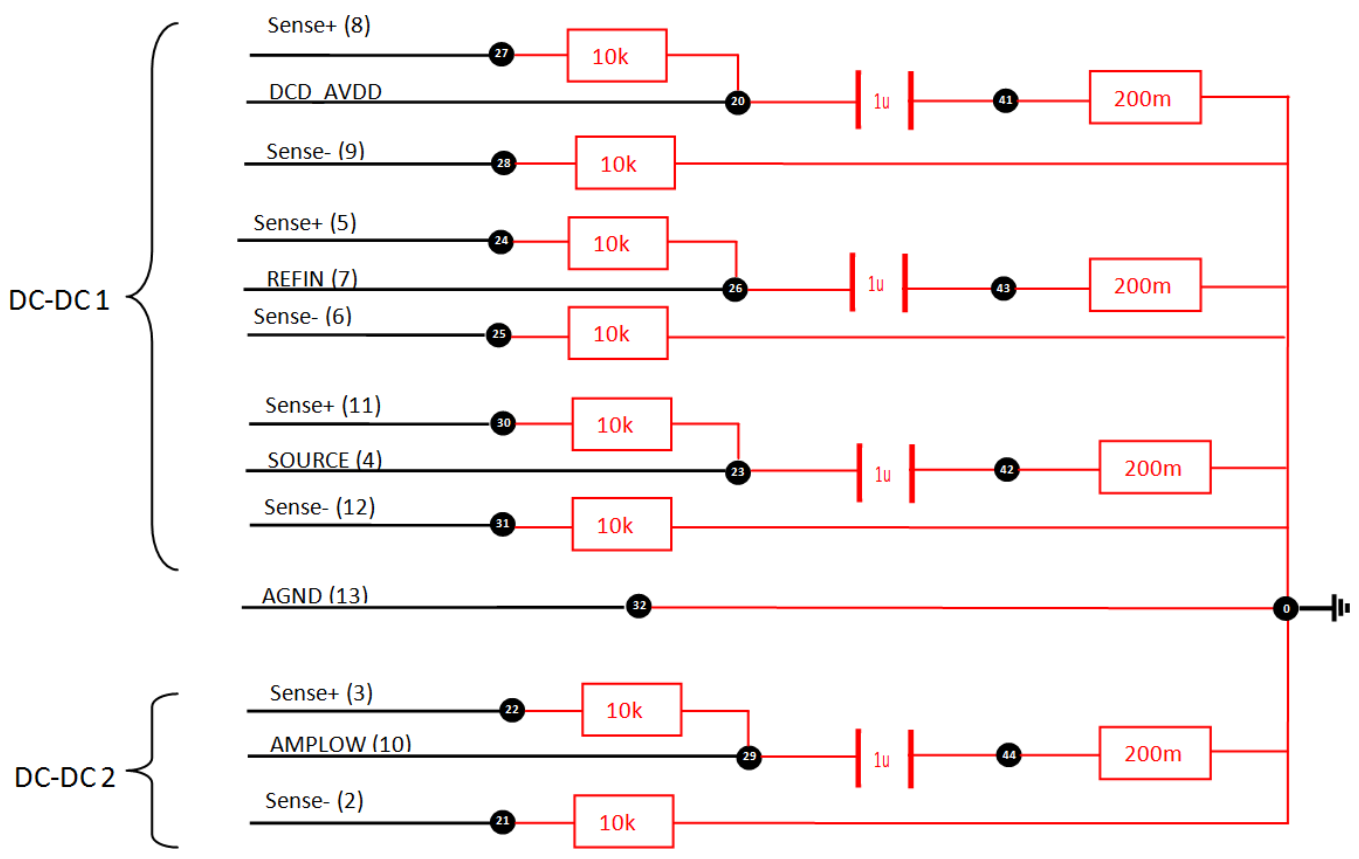

Figure 11. Model for load terminals (DC-DC 1 and 2).

The CM noise injection is modeled as a voltage source connected between the positive terminals of one DC-DC and the ground (figure 12). A capacitor of $1 \mu \mathrm{F}$ is used to model the adjoining DC-DC.

Figure 13 and figure 14 show the transfer functions of $\mathrm{CM}$ noise resulting from the simulation in the $100 \mathrm{kHz}-100 \mathrm{MHz}$ frequency range when CM noise is injected in DC-DC 1 (these graphs show the noise transfer function along the conductors connected to this converter).

As the results show, the voltage gets attenuated due to load filtering. As for the CM current, some degree of amplification is detected around $1 \mathrm{MHz}$, though the cabling resonance is generally attenuated as well due to the high cable resistance at higher frequencies. Similar results have been obtained with the other power supplies $(2,3,4,5,6)$. 


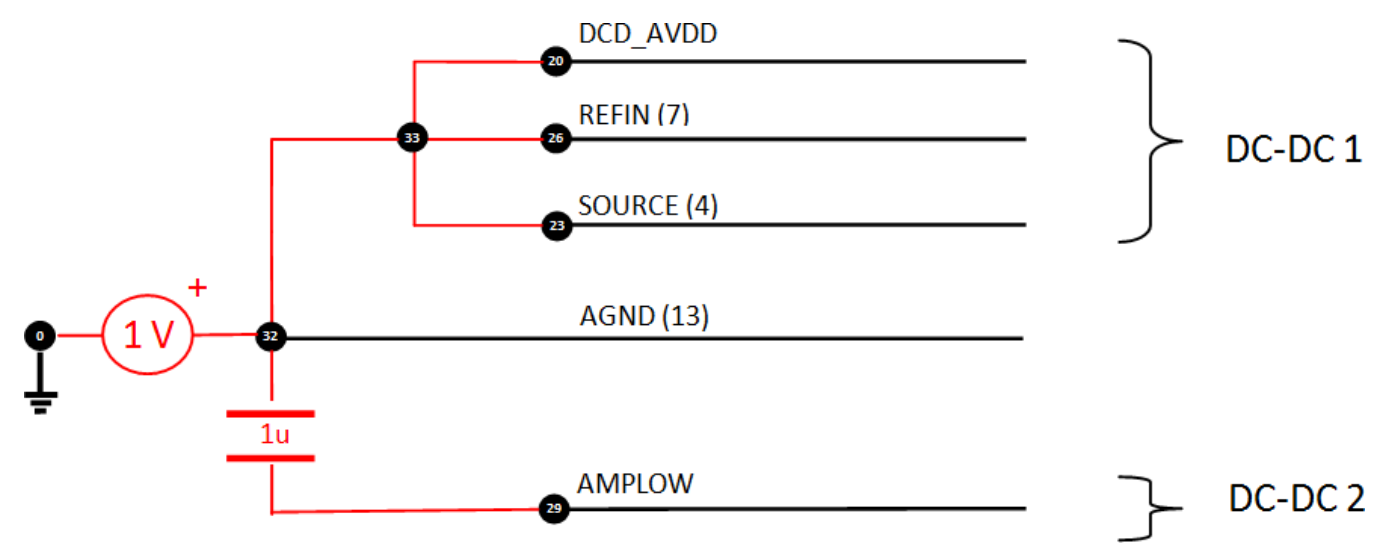

Figure 12. Model for CM noise injection in DC-DC 1.

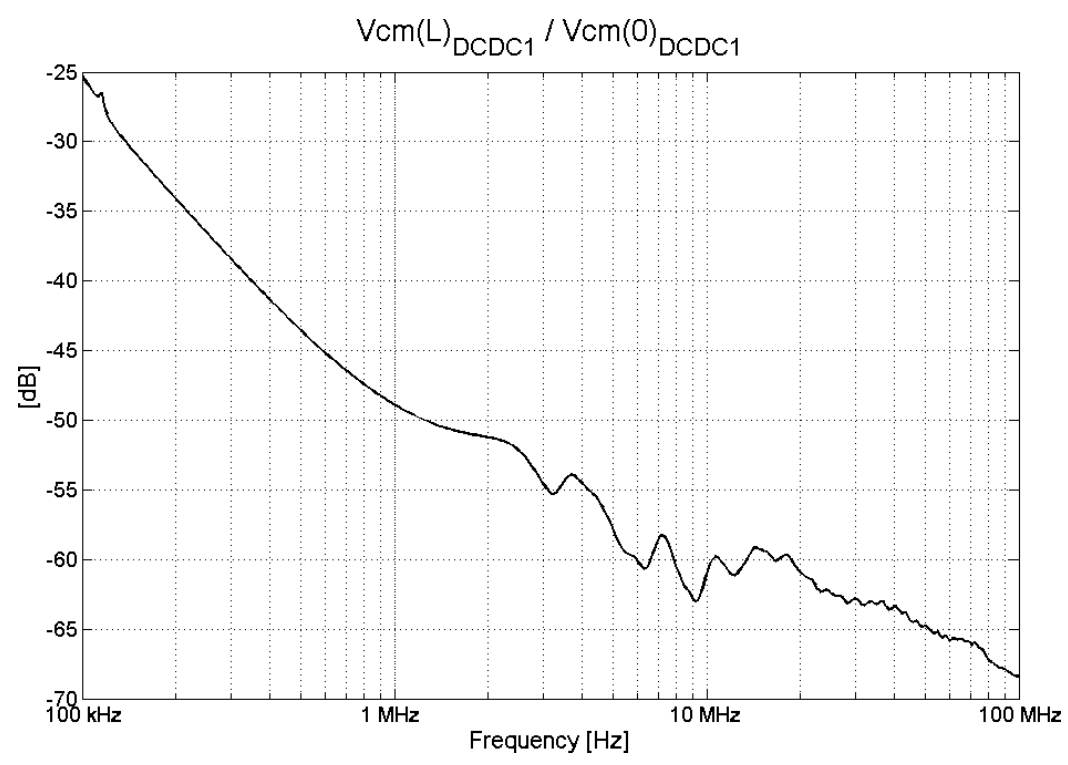

Figure 13. Voltage CM transfer function (noise injection in DC-DC 1).

The noise coupling between converters is analyzed in the next plots. Figure 15 shows the coupling transfer function of noise current in converters 1 and 2, as well as sensing lines, when noise is injected in converter 1 .

Noise coupling has a much lower effect on the sense lines as these lines have a higher impedance. It can be also observed that noise coupling in converter 2 is strong (a quite similar profile is observed in both 1 and 2 converters) despite the fact that noise is injected only in converter 1 . This is due to the fact that both converters share the same return conductor, which defines the noise profile. When taking a look at the noise in other converters, coupling effects are significantly lower. Figure 16 shows the noise at the end of each converter line when CM noise is injected in converter 4.

The higher noise levels are present in converters DC-DC 4 and DC-DC 5 since they both share the STGND return conductor. In this case, the noise level in the other converters ( 1 and 2 ) is lower but not negligible due to the induced noise currents running through the inner shield that embraces the inner conductors. These currents in the shield appear as a result of the noise injected in the 


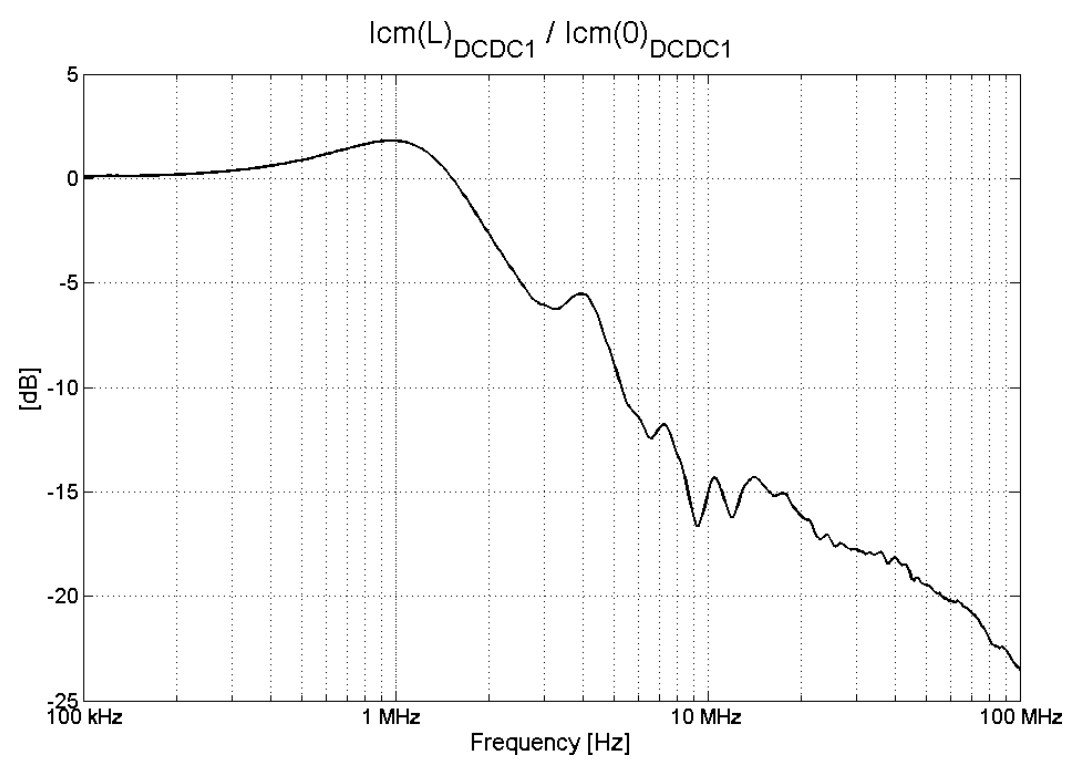

Figure 14. Current $\mathrm{CM}$ transfer function (noise injection in DC-DC 1).

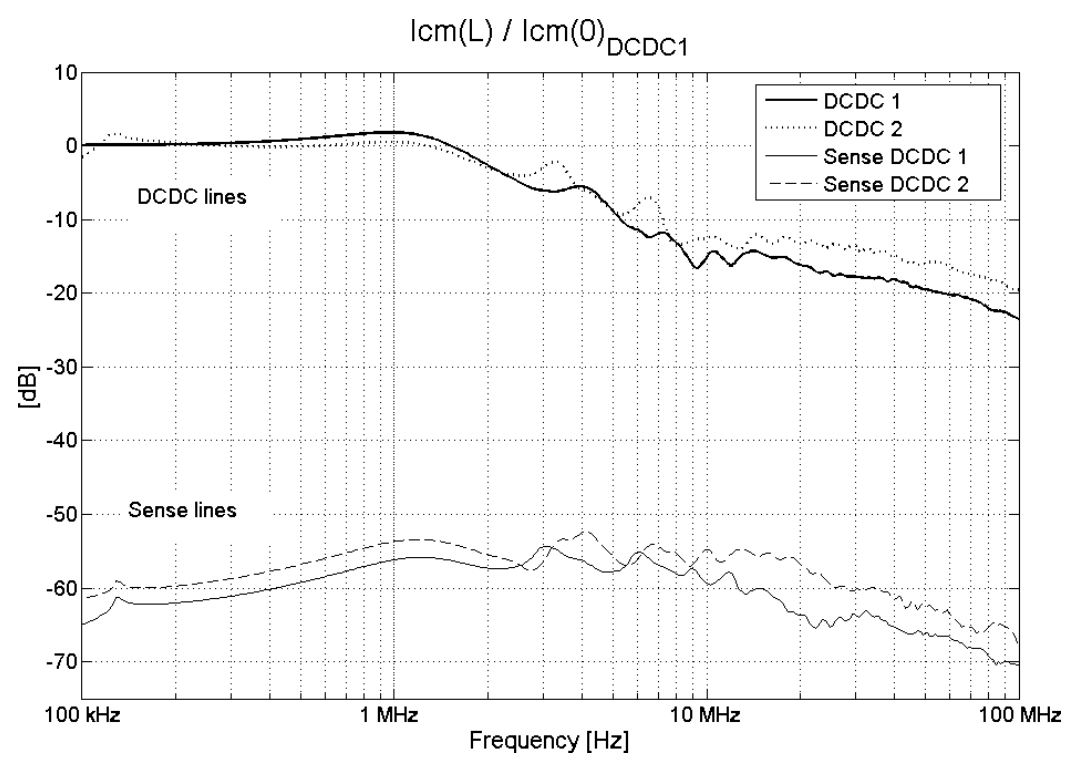

Figure 15. Current CM coupling transfer function (injection in DC-DC 1).

external system, and they get increased by a low impedance connection at both ends of the shield (shield grounding).

\section{Differential mode noise propagation}

In this section, noise propagation through each line and noise coupling among lines are studied when DM noise is injected by power supply units, which has an impact on ripple noise level at the entrance of the FEE. 


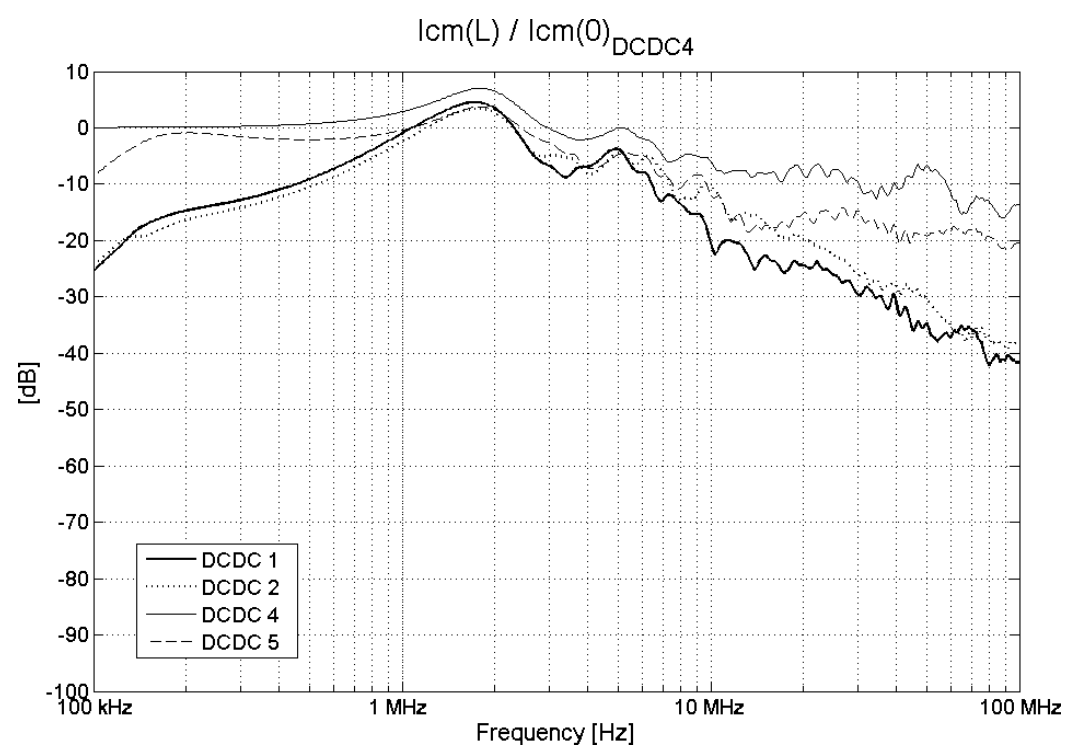

Figure 16. Current CM coupling transfer function (injection in DC-DC 4).

DM injection is modeled with a voltage source connected between the two output terminals of one converter, as shown in figure 17 for DM injection in converter 1.

This case yields the results shown in figure 18 and figure 19 where the DM noise voltage and current are computed between each conductor and the corresponding common return. The results show the effect of the common return as coupling link between the injected lines and the ones in adjoining converters (Amplow), which also takes place with DM noise.

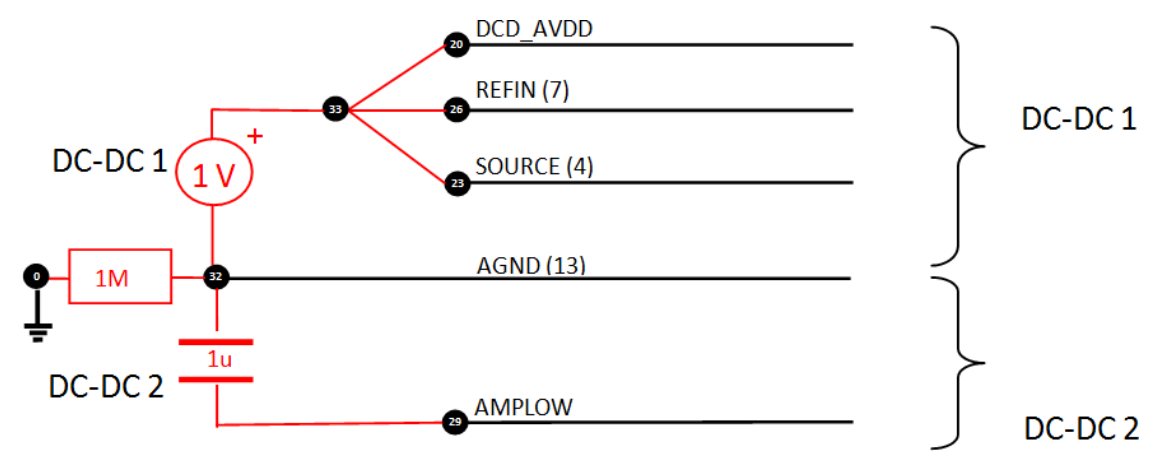

Figure 17. Model for DM injection in DC-DC 1.

Voltage is well attenuated due to DM capacitors, while the current gets amplified (however this is not expected to cause radiation issues because of the return path compensation). Similar effects are observed in the other power supplies of the system. 


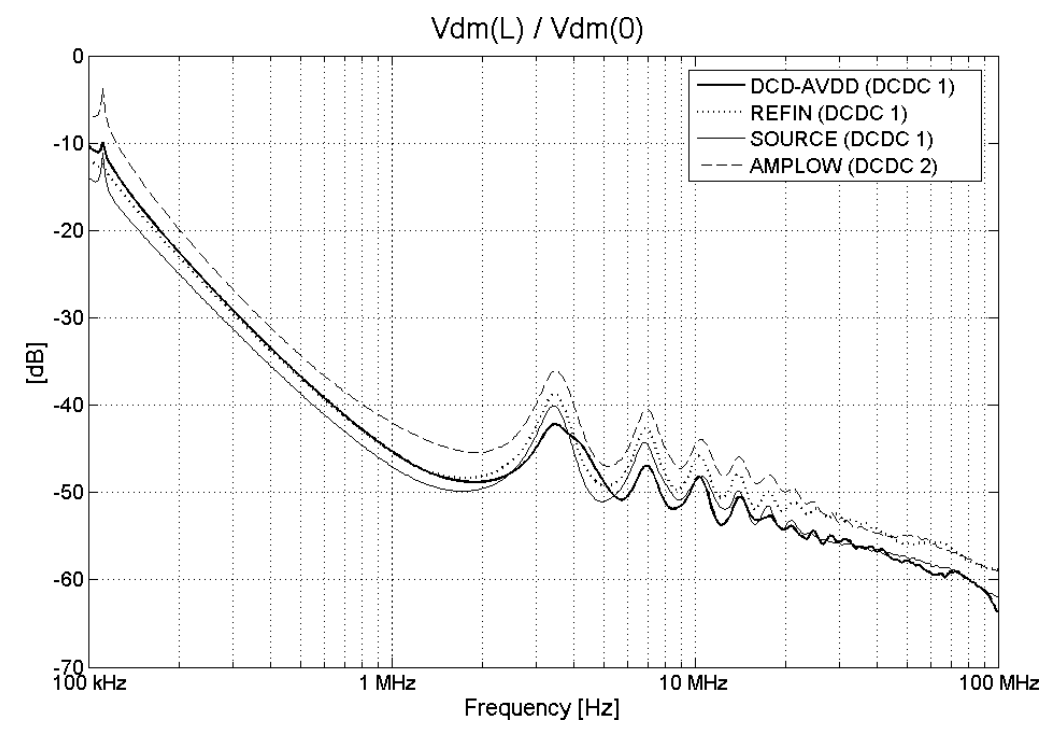

Figure 18. Voltage DM transfer function in signals of converters $1 \& 2$ (injection in DC-DC 1).

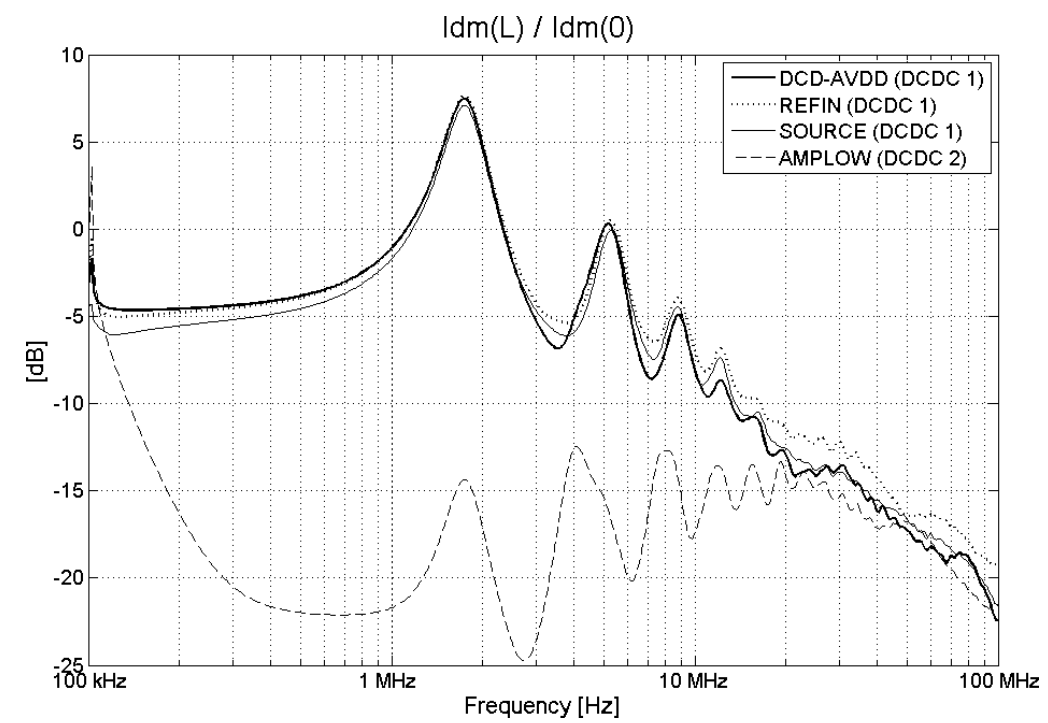

Figure 19. Current DM transfer function in signals of converters $1 \& 2$ (injection in DC-DC 1).

\section{Currents in the shield}

The shield plays an important role in the attenuation of two types of noise:

- Ground currents: these may involve currents flowing through the external shield caused by voltage differences at the connection points of the cable shield.

- External radiated fields: incident radiated waves that illuminate the cable from the external environment.

The connection of internal and external shields may have an impact on the noise distribution across the cable due to shield currents. The effect of these connections on the amount of noise coupled into the internal cables is evaluated in this section. 


\subsection{Ground currents}

The effects of internal shield connections are analyzed after a ground voltage is applied between the external shield and the cable reference as shown in figure 20. The inner shield is also connected to ground on both sides, with a $Z_{c}$ impedance at the source terminal. Two connections for the inner shield are studied: the inner shield connected directly to ground on both sides of the line (modelled with $Z_{c}=0 \Omega$ ), and the inner shield directly grounded only on one side (modelled with $Z_{c}=150 \Omega$ ). The reason for choosing this value of impedance is the fact that the magnitude $150 \Omega$ is used as the normalized impedance for CM signal propagation studies in cables. The noise coupling to the cable is then analyzed in the whole cable as well as in each system (Analogue system / Steering system).

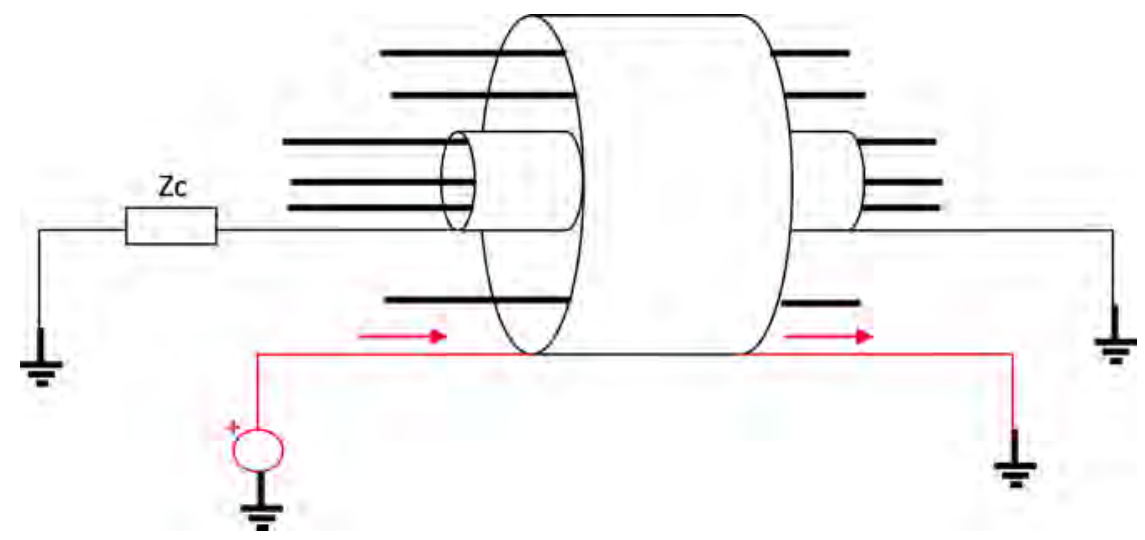

Figure 20. Model for ground currents.

Figure 21 shows the noise coupling in the whole set of conductors of the cable when these ground currents flow through the external shield. The coupling is quantified as the CM transfer function ratio between the external shield (at injection point) and the whole cable (at the end of the line).

When the inner shield is connected to ground through a higher impedance, currents induced in the shield decrease and, as a result, the CM noise induced in the whole set of conductors through the inner shield transfer impedance is lower below $2 \mathrm{MHz}$, reducing therefore the noise computed over the whole set of conductors.

The noise coupling into each of the cable systems is assessed in figure 22, where the CM transfer function ratio is computed between the external shield (at injection point) and the group of conductors that form each system (at the end of the line).

The observed effect is a higher noise coupling to the inner system (ANG system) when the impedance connection of internal shield is lower. As the figure shows, noise transfer into the inner system (AGND) is lowered significantly when the inner shield connection is made through the $150 \Omega$ impedance. In this case, currents in the inner shield induced by the noise in the external shield through the transfer impedance are much lower and thus, the noise that is coupled into the inner conductors decreases. Indeed, higher levels of noise are found in the inner AGND system when the inner shield is connected on both sides. 


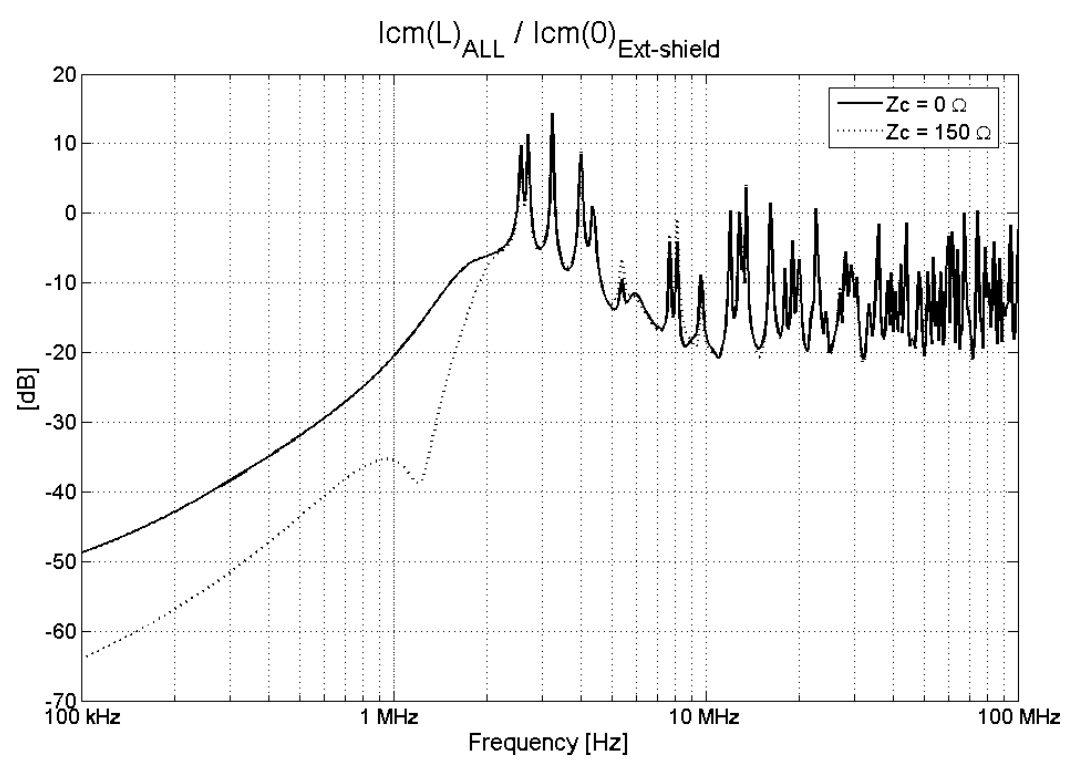

Figure 21. Current CM transfer function for different inner shield connections (CM noise computed over the whole cable.

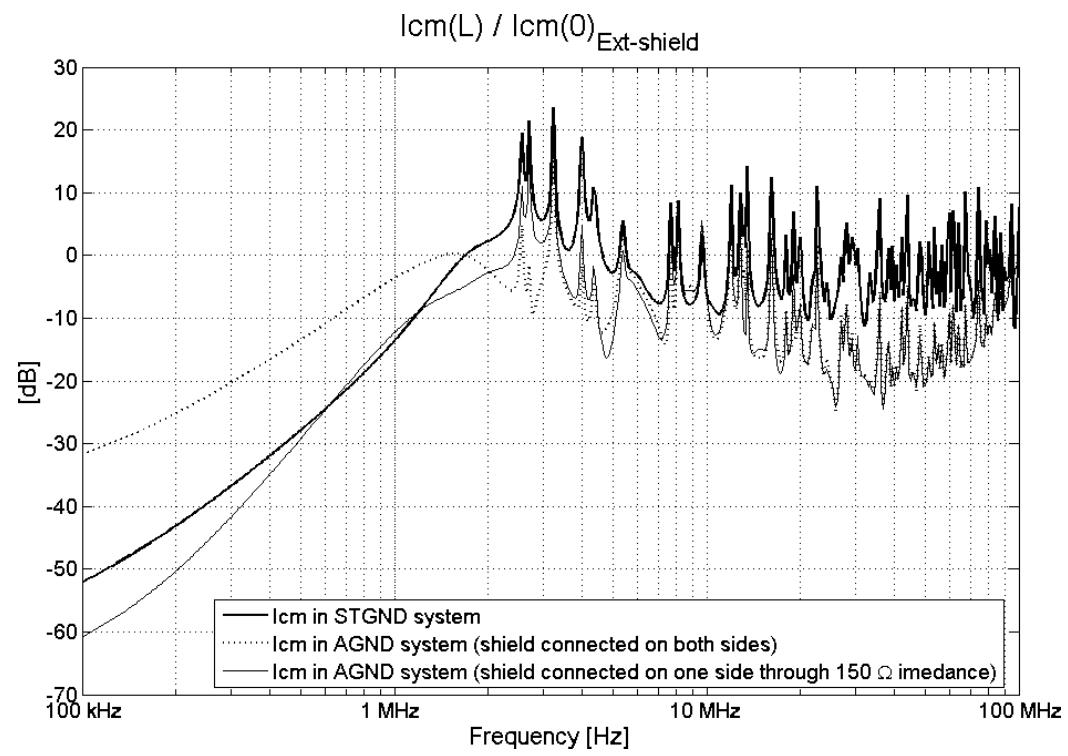

Figure 22. Current CM transfer function coupled to Steering (STGND) and Analogue (AGND) systems.

\subsection{Radiated field (ambient noise)}

This section is focused on the effects of an incident electromagnetic field on the cable and the impact that the shield causes on the noise in the conductors. The incident radiated perturbation is modelled as a uniform plane-wave excitation $(1 \mathrm{~V} / \mathrm{m})$ polarized at one direction.

The effects of this wave can be modelled in the cable as a voltage and current sources distributed in each line as shown in figure 23 [21]. From this scheme, the equations for the wave contributions 


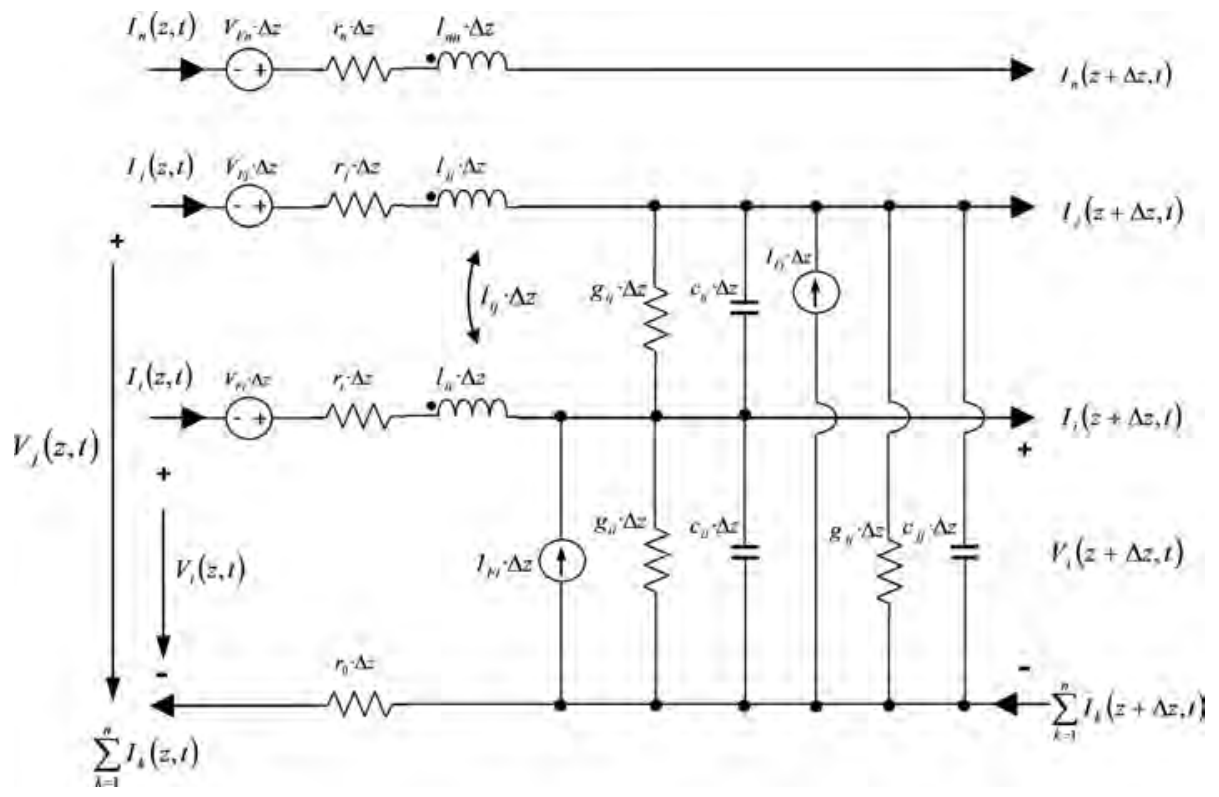

Figure 23. Distributed MTL for external field.

in the MTL model can be expressed as [21]:

$$
\begin{aligned}
& V_{F}(z)=2 h \widehat{E}_{0}\left[\frac{\sin \left(\beta_{x} h\right)}{\beta_{x} h}\right] e^{-j \beta_{z} Z}\left(j \beta_{z} e_{x}-j \beta_{x} e_{z}\right) \\
& I_{F}(z)=-j 2 C . h . \widehat{E}_{0}\left[\frac{\sin \left(\beta_{x} h\right)}{\beta_{x} h}\right] e^{-j \beta_{z} Z}\left(e_{x}\right)
\end{aligned}
$$

where $h$ is the distance from the conductor to the reference plane, $E_{o}$ is the complex amplitude of the sinusoidal wave and $C$ is the capacitance matrix of the conductors.

The components $e_{x}, e_{y}$ and $e_{z}$ define the direction of the electric field according to the reference system of figure 24 . In the present case, the electric field is perpendicular to the cable length:

$$
e_{x}=1, e_{y}=e_{z}=0
$$
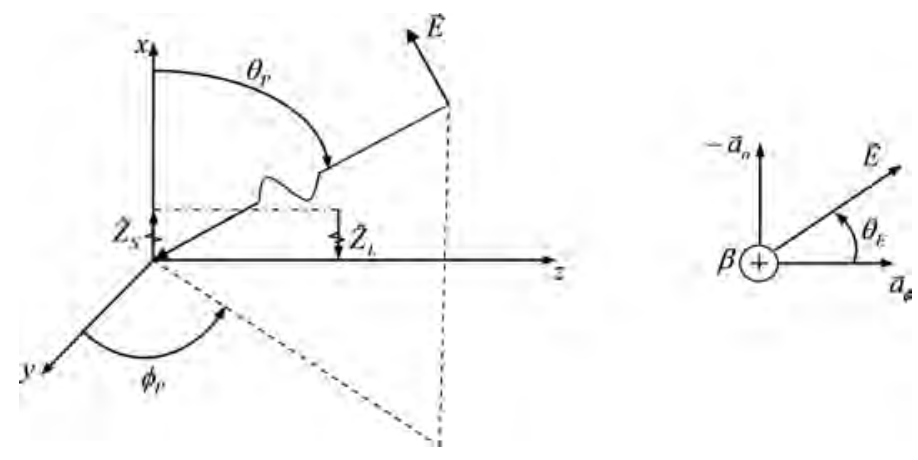

Figure 24. Characterization of incident field as uniform plane wave. Rectangular coordinate system. 
whereas $\beta_{x}, \beta_{y}$ and $\beta_{z}$ are the projections of the phase constant $\beta$ on this reference system ( $\beta$ can be computed with the frequency, permeability and permittivity constants of the medium):

$$
\begin{aligned}
\beta_{x} & =-\beta \cdot \cos \theta_{p} \\
\beta_{y} & =-\beta \cdot \sin \theta_{p} \cdot \cos \varphi_{p} \\
\beta_{z} & =-\beta \cdot \sin \theta_{p} \cdot \sin \varphi_{p} \\
\beta & =\omega \sqrt{\mu \varepsilon}
\end{aligned}
$$

Once the external wave is added to the model, two cases are considered:

- No external shield (this case has been chosen to model a case in which shield is not connected).

- External shield connected to ground at both ends of the line.

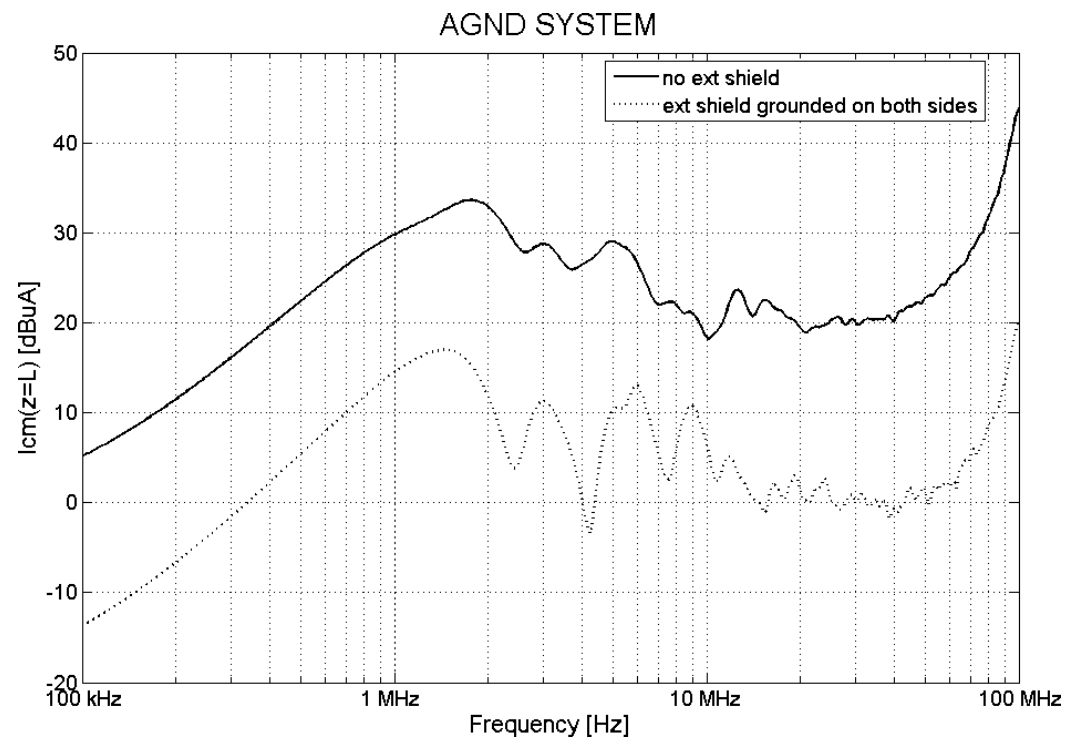

Figure 25. CM current noise for Analogue system.

During this study, the internal shield has been connected at both ends (worst scenario). In this case, the CM noise profile is obtained in each one of the systems that form the cable (figure 25 and 26).

As the results show, the noise rejection is significantly improved when the external shield is connected at both ends of the cable.

\section{Conclusions}

This paper has presented the noise propagation issues of PXD power cable. The results have been obtained using MTL models to simulate the geometry effects of the conductor systems that form the complex structure of the bundle. Parameter uncertainties are taken into account through a Monte Carlo approach which has been applied in the simulations. The study has produced useful information for PXD integration aspects and coordination of shield connection. 


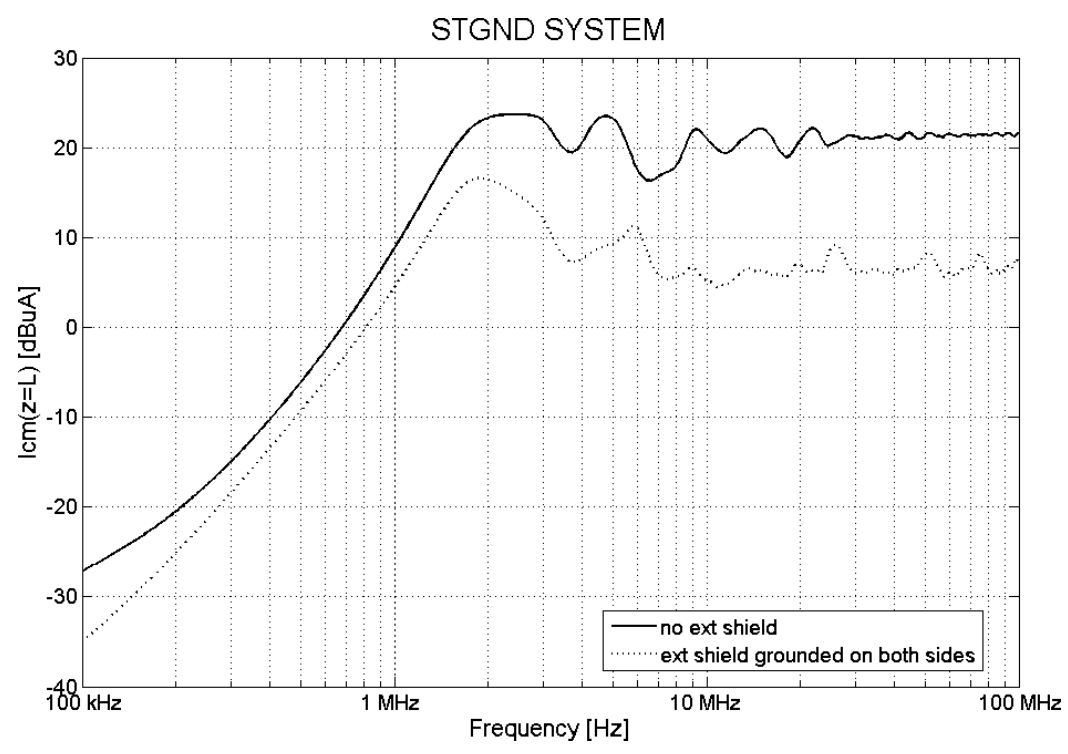

Figure 26. CM current noise for Steering system.

The CM and DM noise levels are similar in cables with common power return while the noise coupled into sense lines or non-common neighboring system is smaller. Results have also shown that CM noise injected in the conductors outside the inner shield might transfer noise into the inner conductors through the shield transfer impedance.

Regarding the shield connections, dis-connection of internal shield to ground seems to present a better performance of the cable against currents in the shield, whereas the connection to ground (both sides) of the external shield is a good barrier against external fields.

These studies will help in the selection of EMI filters for the front-end electronics low-voltage inputs and conducted emission levels required for the power supplies in order to implement properly the grounding and shielding strategies.

\section{Acknowledgments}

The authors want to thank the DEPFET PXD Collaboration for the support of this work. This Project has received funding from Ministerio de Economia (Spain) under grant agreement FPA2014-55295C3-3-R. One of the authors (C.R.) wants to thank the Department of Energy (U.S.A.) for the support of his work under contract No. DEAC02-76CH03000 and DE-AC02-76SF00515.

\section{References}

[1] P. Krisan, Particle identification at Belle II, 2014 JINST 9 C07018.

[2] DEPFET collaboration, F. Lütticke, The Belle II DEPFET pixel detector, 2013 JINST 8 C02006.

[3] K. Lautenbach et al., The Belle II Pixel Detector Data Acquisition and Background Suppression System, 2017 JINST 12 C06023.

[4] D. Dutta et al., Belle II Silicon Vertex Detector, 2017 JINST 12 C02074. 
[5] R. Redl, Electromagnetic Environmental Impact of Power Electronics Equipment, Proc. of the IEEE. 89 (2001) 926.

[6] P.R. Clayton, Introduction to Electromagnetic Compatibility, Wiley-Interscience, (2006).

[7] P.R. Clayton, Analysis of multi-conductor transmission lines, Wiley-IEEE Press, (2007).

[8] T.S. Pang, P.L. So, K.Y. See and A. Kamarul, Common-Mode Current Propagation in Power Line Communication Networks Using Multi-Conductor Transmission Line Theory, in proceedings of the IEEE International Symposium on Power Line Communications and Its Applications (ISPLC '07), 26-28 March 2007, pp. 517-522.

[9] L. Znamirowski and O.A. Palusinski, Algorithm for Accurate Capacitance Matrix Measurements of the Multi-conductor Structure for VLSI Interconnections, private note.

[10] L. Znamirowski and O.A. Palusinski, Analysis of error propagation in computing the Maxwell matrix of multi-conductor structure from measurements, IEEE Proc. Sci. Meas. Tech. 145 (1998) 117.

[11] S.A. Pignari and A. Orlandi, Long-Cable effects on conducted emissions levels, IEEE Trans. Electromagn. Compat. 45 (2003) 43.

[12] A. Ciccolella and F.G. Canavero, Stochastic Prediction of Wire Coupling Interference, proceedings of the IEEE International Symposium on Electromagnetic Compatibility, (1995), pp. 51-56.

[13] I. Echeverria, F. Arteche, M. Iglesias, A. Pradas, J. Piedrafita and F.J. Arcega, Common Mode Noise Propagation and Effects in a Four-Wheel Drive Electric Vehicle, IEEE Trans. Electromagn. Compat. 60 (2018) 132.

[14] F. Arteche, C. Rivetta, M. Iglesias, I. Echeverria, A. Pradas and F. Arcega, Noise propagation effects in power supply distribution systems for high-energy physics experiments, 2017 JINST 12 P12004.

[15] P. Kodys, High resolution DEPFET active pixel sensors for the Belle II experiment, in proceedings of the 2nd International Conference on Advancements in Nuclear Instrumentation Measurement Methods and their Applications (ANIMMA), 6-9 June 2011, pp. 1-5.

[16] F. Arteche and C. Rivetta, Effects of CM and DM noise propagation in LV distribution cables, in proceedings of the 9th Workshop on Electronics for LHC experiments - LECC2003, Amsterdam, October 2003, pp 380-385.

[17] S. Canigia and F. Maradei, Equivalent circuit models for the analysis of coaxial cables immunity, in proceedings of the IEEE International Symposium on Electromagnetic Compatibility, August 2003, Volume 2, pp 881-886,

[18] A. Beltramelli, F. Grassi, G. Spadacini and S.A. Pignari, Modeling conducted noise propagation along high-voltage DC power buses for electric vehicle applications, in proceedings of the 2014 International Conference on Connected Vehicles and Expo (ICCVE), 3-7 November 2014.

[19] L. Jung and J. Luiken ter Haseborg, Evaluation of measured complex transfer admittance for the characterization of shield inhomogeneities of Multi-conductor Cables, IEEE Trans. Electromagn. Compat. 41 (1999) 460.

[20] N. Mora, F. Rachidi, P. Pelissou and A. Junge, An Improved Formula for the Transfer Impedance of Two-Layer Braided Cable Shields, IEEE Trans. Electromagn. Compat. 57 (2015) 607.

[21] F. Arteche, EMC: A Mapping for the CMS Experiment, CERN-THESIS-2004-027. 